\title{
Sustainability of economic systems and business enterprises
}

\author{
Svetlana Kalyugina ${ }^{1 *}$, Natalia Snegireva ${ }^{2}$, Zaur Shalashaa ${ }^{3}$, Polina Shmygaleva ${ }^{4}$ \\ ${ }^{1}$ North-Caucasus Federal University, Pushkin str.1, Stavropol 355009, Russian Federation \\ ${ }^{2}$ North-Caucasus Social institute, Goleneva str. 59A, Stavropol, 355000, Russian Federation \\ ${ }^{3}$ Institute of Economics and Law, Academy of Sciences of Abkhazia, Sukhum, Dzizdzaria str. 40, \\ Abkhazia \\ ${ }^{4}$ Institute of Economics and Law, Stavropol Branch of RANEPA, Lermontova str. 189, Stavropol, \\ 355002, Russian Federation
}

\begin{abstract}
Our paper analyses the issues of sustainability of economic systems and business enterprise at micro and meso levels. Dynamics are analysed in a global bio-geophysical subsystem linked to the macroeconomic system, the environment and the human economy. The paper proposes a conceptual framework that looks into the compromise between economic growth and sustainability and concludes that both can be achieved if relevant efforts are spent and funds are allocated. Moreover, it analyses the risks and assesses economic and financial stability using the Altman and Altman-Sabato models. In addition, the research addresses the role of the macroeconomic system, the environment and the human economy in the sustainable development of ecosystem functions and its impacts on business enterprises. Our results might become the guidelines for the governments seeking to combine the development of their economic systems with the principles of sustainable development.
\end{abstract}

\section{Introduction}

In general terms, sustainability can be considered profit-making by combining profits with sustainability values by using a combination of elements of environmental, social, economic and economic development in the microeconomy $[1,2]$. These include the use of renewable energy, energy efficiency, water saving, waste management, environmental protection and waste management. Many developing countries can skip the ruthless industrialization model and integrate directly into a clean, sustainable development model that focuses on the increased use of renewable energy to supply their growing needs [3]. Sustainable development is a broad term that includes all forms of growth to meet the needs of the current generation without endangering future generations. The Unite Nations defines sustainability as "a form of the economic and social development in the micro-level economic system" [4].

\footnotetext{
*Corresponding author: skaliugina@ncfu.ru
} 
The essence of economics is to formulate the welfare - the welfare of the people - by maximizing the social welfare function (SWF) [5]. Hence the link between economics and sustainable development. The principles for sustainable development are intertwined with sound economic principles presenting a suitable and solid guide for economic actors. In another words, the economic activities that create jobs, income - earning opportunities for jobs and economic growth create opportunities to achieve the best results for the sovereign wealth funds. This is the aim of economic operators, who focus on maximising profits not only for themselves but for society as a whole. Since the economy is the source of human activity, effective governance is crucial to achieving sustainable development [6]. It is imperative that governments undertake the necessary work to provide basic services and coordinate the activities of economic actors in order to ensure that strategies for achieving sustainable development are coordinated. Responsible governments will ensure proper coordination of economic activities and coordination between government, private and public sectors [7].

In fact, direct and indirect cooperation in combination with open innovations (e.g. open source and open access) exhibits a variety of dynamic interactions in open innovations $[8,9]$. The role of open cooperation in the sustainable development of ecosystem functions is very important here. Open innovation offers an opportunity for cooperation between the macroeconomic system, the environment and the human economy. None of these anthropocentric frameworks takes into account the dynamics of ecological systems, but all analyse the system and its processes, whether or not they are relevant to humans or the environment.

\section{Indicators for assessing economic and financial stability}

Economic and financial stability take into account business forecasts and assesses the risk to the financial system of economic and financial stability $[10,11]$. In addition to assessing risks to households and businesses, the macroeconomic forecasts and stress tests are conducted. Stress tests have become an important part of the process of risk assessment in the banking sector and can shed light on how exposed financial institutions are to macroeconomic changes $[12,13]$. These models explain the actual losses quite well and also have a good result - samples of real estate, but not as good as the bank's own data. It turns out that these changes have a positive impact on the growth of economic growth and financial stability.

However, one can note that growth in selected economics is only positively determined by the ratio of turnover to market efficiency, due to the presence of FDP [14]. In addition, one can also note that the ratio of traded shares to total assets in the banking sector and the total number of bank loans is both positively and significantly influenced by economic growth, regardless of whether indicators for the development of the banking sector are selected [15]. In this context, it should be noted that the number of scientific papers and econometric studies examining the relationship between economic growth and financial stability and the development of the banking sector has increased significantly over the last two decades.

Nevertheless, the main conclusion that comes from the above is that there is a positive correlation between the ratio of sales to market efficiency and growth in selected economies. Balancing financial stability, innovation and economic growth and other economic indicators in economic development. Although known sources for the relationship between financial stability and economic growth, including the International Monetary Fund (IMF), the World Bank and the European Central Bank, new sources have emerged in recent years. Financial stability represents a lack of instability, but this approach is based on the assumption that the basis for financial sustainability is the ability of financial markets to reach their full potential 
without the need for central bank intervention. This approach to understanding "financial sustainability" emphasises the role of the financial sector in economic growth and stability, and requires an understanding of its role in the economy as a whole and its relationship to economic and financial growth [16, 17]. For example, in China the Bank of China has its main objectives aimed at ensuring price stability at home, managing the exchange rate and promoting economic growth. The bank recently promised to maintain its prudent monetary policy by fine-tuning its policies - while respecting its long-term inflation target of $2.5 \%$ [18]. One needs to monitor the conditions and developments of the financial system as part of the economic environment, and monitoring of financial stability receives regular attention. After the financial crisis, the Federal Reserve in the United States developed a framework for systematically tracking risk. Stricter macroprudential measures can tighten financial conditions, increasing the likelihood that monetary policy responses will be needed. There must be a clear and consistent assessment of the financial and economic stability of the United States economy [19]. When making monetary policy decisions, we must be aware of the risks to the economy, the financial markets and the global economy as a whole. Regular attention is important, as we have learned from the financial crisis, because vulnerabilities can build up over time, even in periods when conditions appear favourable. The idea behind measuring financial stress is to prevent it from culminating in systemic risk. The indicators are then combined to create an index that uses the appropriate statistical techniques to reflect its evolution in the economy [20].

Since different market variables behave differently and due to different market variables, a single composite index can be used and expected to better understand the prevailing stress. Improving supervision and financial supervision requires a better understanding of financial stress and its impact on financial stability. Central banks can measure financial burdens by creating a Financial and Stress Index (FSI) to monitor the functioning and resilience of the financial system. The IMF has developed the Financial Stability Index (FSI), the world's first and most comprehensive financial and economic stress measurement. These indicators of financial sustainability include one that characterises the financial stability of a country's financial system and its financial institutions. These indicators include aggregated information on the level of risk in financial markets, as well as indicators that characterise the quality of the markets in which financial institutions operate and the level of liquidity in those markets $[21,22]$.

In order to define the integral indicator for assessing economic and financial stability the Z-model devised by Altman [23] can be used. The model can be presented in the following way:

$$
Y_{0}=0.012 X_{1}+0.014 X_{2}+0.033 X_{3}+0.006 X_{4}+0.999 X_{5}
$$

where $\mathrm{X}_{5}$ - sales profit/A.

There is also an improved version of the Altman model that is called the Altman-Sabato model [24]. This model has high accuracy but does not take into account the specifics of particular industries. The model can be presented in the following form:

$$
p_{Z}=1 /\left(1+e-4.28-0.18 X_{3}+0.01 X_{1}-0.08 X_{2}-0.02 X_{3}-0.19 X_{4}\right)
$$

where $p_{z}$ - possibility of bankruptcy according to Altman-Sabato model;

$\mathrm{X}_{1}=$ short-term liabilities/assets;

$\mathrm{X}_{2}=$ net profit $/ \mathrm{A}$;

$\mathrm{X}_{3}=$ monetary funds/A; 
$\mathrm{X}_{4}=E B I T /$ receivable interests.

In the research literature, the following modification of the model are also used for calculations of the same relationship:

$$
R O E=R O S * \text { total assets turnover * leverage ratio }
$$

where ROS - return on sales.

where:

$$
R O E=t * r * R O S * \text { total assets turnover * leverage ratio }
$$

$\mathrm{t}$ - tax burden ratio,

$\mathrm{r}$ - percent burden ratio.

Hence, equations (3) and (4) determine the profitability of sales based on the net profit which allows comparing disparate values such as net profit and turnover.

\section{Value added and net profit in sustainable development}

Company managers need to consider equity to adjust interest-rate relationships between owners and operators, adjust taxes - correct the cost of capital, and improve investment levels. Economic value creation and net profit in sustainable development both embed the analysis of the economic value of equity and capital. Growth refers to a company's ability to pursue sustainable development and is an important indicator for measuring the company's future performance based on the estimated rates of revenue growth in this paper. Growth means that companies of scale are growing, market competitiveness is increasing and profitability of companies is increasing. A general definition of business growth is the potential value that a company continuously achieves by exploiting or exploiting unused resources. In addition, managers in low-growth companies with little development potential tend to be overinvested, while high-growth companies with high development potential (e.g. large companies) are abundant, and that lower-growth companies have little or no development opportunities. The terms used to describe the economic justification of a proposed investment can be understood as a benefit that is exactly in line with the cost of the proposed project.

Similarly, the benefits that arise at the time of cost collection will also bring the same benefits that will continue to accrue in the future. In this sense, ERR is the result that not only the cost of living in the partner country is taken into account, but also the benefits for the country as a whole. A crucial basic concept is that sustainable business models create and use ecological and social surpluses, by which we mean sustainability investments that can have secondary value through higher returns. This will allow cereal producers to achieve net $\mathrm{CO}_{2}$ offsets from their production by reducing emissions. Agricultural banks can include net greenhouse gas sequestration in the terms of payment of the offsets, thereby promoting the sustainability of farms and enabling the bank to accumulate new assets from available carbon offsets. They can also offer farmers preferential financing for the introduction of renewable agriculture or include carbon credits in their payments. A fundamental prerequisite for sustainability is the transformation of an industry's business model (business models) to reflect value for customers and society by accepting a premium for achieving performance levels and achieving certain performance goals.

Consumers and businesses are also offering businesses behavioural skills as new assets in business, and as we have seen, they are paid premiums for this. A major challenge for the research community is to develop more appropriate business models that capture and reflect 
this added value by providing sustainable buildings that are operated while reducing resource consumption and maintaining adequate utilities for residents. However, this has not been a priority for the academic community and is indeed not even a priority for many in the business community. To limit managers' investment behaviour and improve investor efficiency, a sensible valuation and index system must be put in place. Performance indicators must be established to determine whether evaluation outcomes can directly change managers' workflows and behaviour. It must also enable fine-tuning and problem-solving, and examine how values can actually be validated in practice, and how performance data can be shared with stakeholders to receive feedback and feed-forward. The EVA is an evaluation index proposed in the 1980s that measures a company's value - its ability to create. This is a method of assessing a company's performance and financial results, based on the value of its invested capital and its ability to create and its financial performance. BOC's ROE and REVA are the lowest on this list, lagging behind other commercial banks. This is acceptable if one takes into account the level of equity and other factors, but you can withdraw it. Analysing for certain reasons, the state-controlled stock exchange trading bank generated low net operating income after tax and paid a large amount of capital, resulting in a low RVA. Overinvestment in state-owned enterprises is more severe compared to private holding companies, but improvements in the external governance environment can prevent overinvestment to some extent. They find that cash dividends can effectively constrain investment behaviour and have a good inhibitory effect. Economic value added is an important factor for the development of sustainable development in China and other countries, especially in rural areas.

\section{Sustainability of enterprise economy}

Sustainable development presents itself as an alternative to such problems by focusing on finding alternatives that meet current and existing needs without compromising on meeting the needs of future generations. Entrepreneurship has proven to be an effective wealth creation mechanism and is seen as a driver of change, innovation and economic growth. Sustainable entrepreneurship builds on the foundations of entrepreneurship and extends it to the environmental and social concerns that are taken into account by existing companies. Sustainable entrepreneurship thus becomes relevant and focuses on preserving nature, supporting the life of communities, and creating services and products that reflect individual well-being - being, the economy, and society. Entrepreneurship is also seen as a viable alternative when faced with environmental, social and economic challenges such as climate change and poverty, as it pursues objectives that go beyond economic benefits. Market opportunities include addressing sustainability concerns by providing new products and services that reduce energy and resource consumption. Sustainable businesses are recognizing the growing scientific evidence and growing evidence that growing social inequalities are destroying the economy, the environment, and global society. They recognize these changes by understanding that the consumer public is increasingly concerned about the challenges of a sustainable world. This module is intended to provide a framework for developing a business plan for the transition to a sustainable business model with a focus on energy efficiency, sustainability and environmental sustainability. The current challenges facing companies worldwide are presented in the context of the United Nations Global Compact [25].

The economic sustainability of companies is to act responsibly and to make a profit without causing undue harm to the world. This means recognizing that even very small businesses are part of a larger global economy. It is important to consider how your business practices affect others ecologically, culturally and socially. Regenerative capitalism addresses precisely the need to restructure the economy and to risk the opportunities and risks 
that the absence of such a change might entail in the short term. Economic sustainability can refer to how an economy functions to protect the social and environmental elements of its business environment and its employees. When small businesses make ethical choices for growth, their owners' benefit, and we look at the benefits that this can bring both globally and at the corporate level. In this article, we want to examine our idea of economic sustainability, ensure that it is interconnected, and consider it as more holistic. The second definition adds environmental and social factors to the mix to sustain economic production, such as water, energy, food, and energy efficiency. Another important economic objective in this context is the Sustainable Development Goal No. 9 (SDG9), a part of the SDGs developed by the United Nations which relates to innovation and infrastructure in industry.

\section{Sustainability of economic systems}

Thence, sustainable development requires improving the quality of life for all by increasing the number of jobs, education, health care and social services for all, reducing poverty by at least $75 \%$, and reducing the use of fossil fuels and fossil fuels - intensive industries [26, 27]. Conservation and the environment: To preserve our ecological heritage and natural resources for future generations and to preserve natural habitats, economically viable solutions need to be developed to reduce resource consumption, stop pollution and preserve the natural habitat. Today's interconnected global economies require an integrated approach to promoting responsible, long-term growth, to ensure that no nation or community is left behind.

People worldwide need access to a wide range of goods and services, from food and energy to health care and education. These include education, health, housing, transport, energy, food, water and sanitation, and health and safety. All these pieces are part of the puzzle of a sustainable society, because they are fundamental parts of everyday life. Sustainable development is a way of thinking that thinks about the development of economic and social systems, not just economic systems. It represents the need to find ways of achieving economically, socially and ecologically sustainable development.

Sustainable capitalism is fundamentally different from environmental protection because it adheres to the principles of social justice, human rights, and the rule of law. It internalizes direct social and environmental costs and benefits, and does not rely on free markets to distribute environmental and social capital. Many people doubt whether a moral and just society can ever be limited and guided by the principles of social justice, human rights and the rule of law.

Although no other economic system has found that it can compete with capitalism in terms of the allocation of resources that are rightfully owned by individuals and economies, capitalism remains open to discussion. Even if sustainable solutions do not yield gains, they will succeed in terms of social justice, human rights, and the rule of law. It is now clear that economies must be designed to reflect the priorities and values associated with maintaining habitable conditions on the planet.

While the way we create value in today's economy depends on a systemic rejection of environmental priorities, design and industry must prioritize the needs of the environment and the economic system. Diversion of the economic design sector towards economic and service structures and systems that support socially distributive and ecologically regenerative design. Achieving a sustainable future will require a set of policies and institutions that keep the economy within the limits set by nature. In this paper, we argue that the acceptance of natural resource constraints that limit the long-term growth of material production and consumption is unnecessary to protect and sustain the biophysical systems that underpin the sustainable development of the global economy and the environment as a whole. 
More significantly, an optimal tax that balances the private benefits and social costs of consumption would support the creation of an economy that strikes an appropriate balance between society's needs and natural resources. In a growth-oriented society, this offers an alternative to critics who warn that the cost of achieving environmental sustainability would jeopardize the economy. This is an important concept that needs to be communicated across various channels and mass media outlets in order to convince the members of the general public that sustainable development is economically viable and does not need to compromise the economic growth and prosperity.

\section{Conclusions and implications}

In this research, we discussed the economic and environmental challenges that people and the planet face and presented solutions to integrate the needs of the planet, people and profit. This is the largest corporate citizenship initiative in the world, addressing the sustainability of businesses and their impact on the environment and human well-being. Environmental and eco-entrepreneurship appears to be able to solve environmental problems by creating economic value. Sustainable value, then, means creating a sustainable business model and its impact on the environment and human well-being - being. Environmental sustainability and the associated corporate strategies that are understood can be incorporated into the creation of sustainable value for companies.

One can see that sustainability therefore consists of three pillars: the economy, society and the environment. This is due to the fact that economics has a number of well-developed areas, such as social psychology, economics and system economics. Economics, in combination with other social and behavioural sciences, is important for understanding the trade-offs that accompany the development of a sustainable economy for all life on Earth and for the long-term sustainability of the planet. The combination of economics and earth system science is crucial to understanding how it might be possible to change human behaviour in order to achieve sustainable development.

Overall, it appears that the application of economic principles and empirical knowledge should be crucial to meet the challenges of sustainable development, given the limited resources of the earth. The economic and earth system sciences, as well as other social and behavioural sciences, have a long and complex history of the humanities. This approach is strongly bottom-up, suggesting that a sustainable future will only be achieved if the biophysical and social conditions needed to support economic activity and human prosperity are maintained for this and the next generation.

\section{References}

1. I. Nesterova, Journal of Cleaner Production, 262, 121382 (2020)

2. T. Vasylieva, S. Lieonov, I. Makarenko, N. Sirkovska, N. (2017). Marketing and Management of Innovations, 4, 350-357

3. A. Rogalev, I. Komarov, V. Kindra, O. Zlyvko, Entrepreneurship and Sustainability Issues, 6(1), 429-445 (2018)

4. United Nations, https://www.un.org/sustainabledevelopment/economic-growth

5. M. Fotros, E. Torkamani, Advances in Mathematical Finance and Applications, 4(2), 89$101(2019)$

6. J. Mensah, S. Casadevall, Cogent Social Sciences, 5(1), 1653531 (2019)

7. M. D. Jensen, Public Administration, 95(1), 249-268 (2017)

8. J. Yun, X. Zhao, K. Park, L. Shi, Sustainability, 12(11), 4379 (2020) 
9. J. Yun, X. Zhao, K. Jung, T. Yigitcanlar, Sustainability, 12(12), 5076 (2020)

10. I. Cabelkova, W. Strielkowski, Society and Economy, 35(4), 513-529 (2013)

11. W. Allen, G. Wood, Journal of Financial Stability, 2(2), 152-172 (2006)

12. C. Sahin, J. de Haan, E. Neretina, Journal of Banking \& Finance, 117, 105843 (2020)

13. P. Gai, S. Kapadia, Oxford Review of Economic Policy, 35(4), 586-613 (2019)

14. S. Adeusi, O. Dada, O. Adeosun, International Journal of Academic Research in Business and Social Sciences 8(9), 1119-1132 (2018)

15. E. Nizam, A. Ng, G. Dewandaru, R. Nagayev, M. Nkoba, Journal of Multinational Financial Management, 49, 35-53 (2019)

16. C. Paun, R. Musetescu, V. Topan, D. Danuletiu, Sustainability, 11(6), 1713 (2019)

17. S. Kalyugina, W. Strielkowski, L. Ushvitsky, E. Astachova, Journal of Security \& Sustainability Issues, 5(2), 297-304 (2015)

18. R. Vasudevan, Review of Keynesian Economics, 9(1), 83-108 (2021)

19. P. Ireland, Journal of Applied Corporate Finance, 31(4), 68-76 (2019)

20. A. Neveu, Journal of Economic Interaction and Coordination, 13(2), 241-281 (2018)

21. M. Power, Review of International Political Economy, 12(4), 577-599 (2005)

22. D. Delpini, S. Battiston, G. Caldarelli, M. Riccaboni, PLoS ONE, 14(5), e0217141 (2019)

23. E. Altman, Journal of Investment Consulting, 19(1), 15-22 (2019)

24. E. Altman, M. Iwanicz-Drozdowska, E. Laitinen, A. Suvas, Applied Economics, 52(37), 4092-4111 (2020)

25. G. Orzes, A. Moretto, M. Ebrahimpour, M. Sartor, M. Moro, M. Rossi, Journal of Cleaner Production, 177, 633-654 (2018)

26. A. Kasych, M. Vochozka, Marketing and Management of Innovations, 2, 298-305 (2017)

27. A. Omri, F. Belaid, Journal of Environmental Management, 278, 111483 (2021) 